\title{
Excitatory amino acid binding sites in the periaqueductal gray of the rat
}

\author{
Roger L. Albin, Richard L. Makowiec, Zane Hollingsworth, Leon S. Dure IV, John B. Penney and \\ Anne B. Young \\ Department of Neurology, University of Michigan, Ann Arbor, MI (U.S.A.)
}

(Received 12 April 1990; Revised version received 22 June 1990; Accepted 23 June 1990)

Key words: Glutamate; Aspartate; Excitatory amino acid; Periaqueductal gray; Pain; Nociception

\begin{abstract}
We used receptor autoradiography to determine the distribution of excitatory amino acid (EAA) binding site subtypes in the periaqueductal gray (PAG) of the rat. $N$-Methyl-D-aspartate (NMDA), kainate, quisqualate-ionotropic, and quisqualate-metabotropic binding sites were all present in the PAG. Distribution was inhomogeneous with greatest density of all binding site subtypes in the dorsolateral subdivision and lowest density in the ventrolateral subdivision. Relative to regions of brain with high densities of EAA binding site subtypes, quisqualate-metabotropic binding sites had the highest relative density and NMDA binding sites the least. The presence of all subtypes of EAA binding sites in the PAG suggests that EAA action within the PAG is likely to be complex.
\end{abstract}

The periaqueductal gray (PAG) is a mesencephalic nucleus implicated in the control of nociception, vocalization and defensive behaviors [2, 8, 9, 13-16]. Physiologi$\mathrm{cal}$, immunocytochemical, biochemical, and $\left[{ }^{3} \mathrm{H}\right] \mathrm{D}-$ aspartate transport studies suggest that excitatory amino acids (EAAs) are important neurotransmitters within the PAG $[1,2,4,7-10,13-16,23]$. EAAs act via multiple receptors named after their prototype agonists [24]. The so-called $N$-methyl-D-aspartate (NMDA), quisqualate (QA), and kainate (KA) receptors all act by control of ion channels. In addition, a second QA preferring receptor linked to inositol phospholipid metabolism (the socalled metabotropic receptor) has been described [21]. Autoradiographic studies have demonstrated the existence of EAA binding sites in the PAG but these studies did not compare EAA binding site subtypes $[10,11,17$, $20,22]$. Similarly, most physiological studies have used iontophoresis or microinjection of nonspecific glutamate agonists into the PAG. To clarify the basis for EAA action in the PAG, we used quantitative receptor autoradiography to examine EAA binding site subtype density and distribution in the PAG.

Seven male Sprague-Dawley rats (175-200 g; Harlan Labs, Indianapolis, IN) were decapitated, the brains extracted from the calvarium and frozen in powdered dry ice. Twenty- $\mu$ m-thick cryostat sections were thawmounted onto gelatin-coated slides and stored at $-20^{\circ} \mathrm{C}$

Correspondence: R.L. Albin, Neuroscience Laboratory Building, 1103 E. Huron, Ann Arbor, MI 48104, U.S.A. for $24-48 \mathrm{~h}$. Sections were taken in the rostral midbrain, approximately $-6.0 \mathrm{~mm}$ from bregma, a level where all anatomic subdivisions of the PAG are present [3]. Assays for NMDA, QA-ionotropic (QA-i), and KA binding sites were performed using conventional techniques [24]. The assay for QA-metabotropic (QA-m) binding sites was performed according to the method of Cha et al. [6]. This method for assaying QA-m binding sites uses $\left[{ }^{3} \mathrm{H}\right]$ glutamate under selective conditions. The pharmacology of $\left[{ }^{3} \mathrm{H}\right]$ glutamate binding under these conditions is identical to that of glutamate stimulated inositol phospholipid turnover, and this binding site has a unique distribution in brain [6]. Briefly, sections were warmed to room temperature, prewashed in ligand buffer for one $0.5 \mathrm{~h}$ at $4^{\circ} \mathrm{C}$, dried under a cool stream of air, and immersed in $4^{\circ} \mathrm{C}$ ligand solution for $45 \mathrm{~min}$. NMDA binding sites were assayed with $65 \mathrm{nM}\left[{ }^{3} \mathrm{H}\right]$ glutamate (spec. act. $=46 \mathrm{Ci} / \mathrm{mmol}$ ) in $50 \mathrm{mM}$ Tris-acetate $(\mathrm{pH} 7.2$ ) with $1.0 \mu \mathrm{M} \mathrm{KA}$ and $2.5 \mu \mathrm{M} \mathrm{QA}$ added. Non-specific binding was assessed with $1 \mathrm{mM}$ NMDA and was less than $10 \%$ of total binding. QA-i binding was assessed with $34 \mathrm{nM}\left[{ }^{3} \mathrm{H}\right](\mathrm{RS})-\alpha$-amino-3-hydroxy-5-methylisoxazole-4-proprionate (AMPA) (spec. act. $=29 \mathrm{Ci} / \mathrm{mmol}$ ) in $50 \mathrm{mM}$ Tris- $\mathrm{HCl}$ plus $2.5 \mathrm{mM} \mathrm{CaCl}$ in the presence of $30 \mathrm{mM} \mathrm{KSCN} \mathrm{(pH} \mathrm{7.2).} \mathrm{Non-specific} \mathrm{binding} \mathrm{was}$ assessed with $1 \mathrm{mM}$ glutamate and was less than $5 \%$ of total binding. QA-m binding was measured with $200 \mathrm{nM}$ $\left[{ }^{3} \mathrm{H}\right]$ glutamate (spec. act. $=46 \mathrm{Ci} / \mathrm{mmol}$ ) in $50 \mathrm{mM}$ Tris$\mathrm{HCl}$ plus $2.5 \mathrm{mM} \mathrm{CaCl}, 100 \mu \mathrm{M} \mathrm{NMDA}$, and $10 \mu \mathrm{M}$ AMPA. Non-specific binding was assessed with $2.5 \mu \mathrm{M}$ 
TABLE I OF RAT PERIAQUEDUCTAL GRAY

All values in femtomoles/milligram protein (S.E.M.). Percent of reference area is the percent of binding in the dorsolateral subdivision compared to an area of known high ligand binding (see text for details). This number provides a reference value for the amount of ligand binding in the PAG versus the rest of the brain. PAG, periaqueductal grey; NMDA, $N$-methyl-D-aspartate binding sites; QA-i, quisqualate-ionotropic binding sites; QA-m, quisqualate-metabotropic binding sites; $\mathrm{KA}$, kainate binding sites.
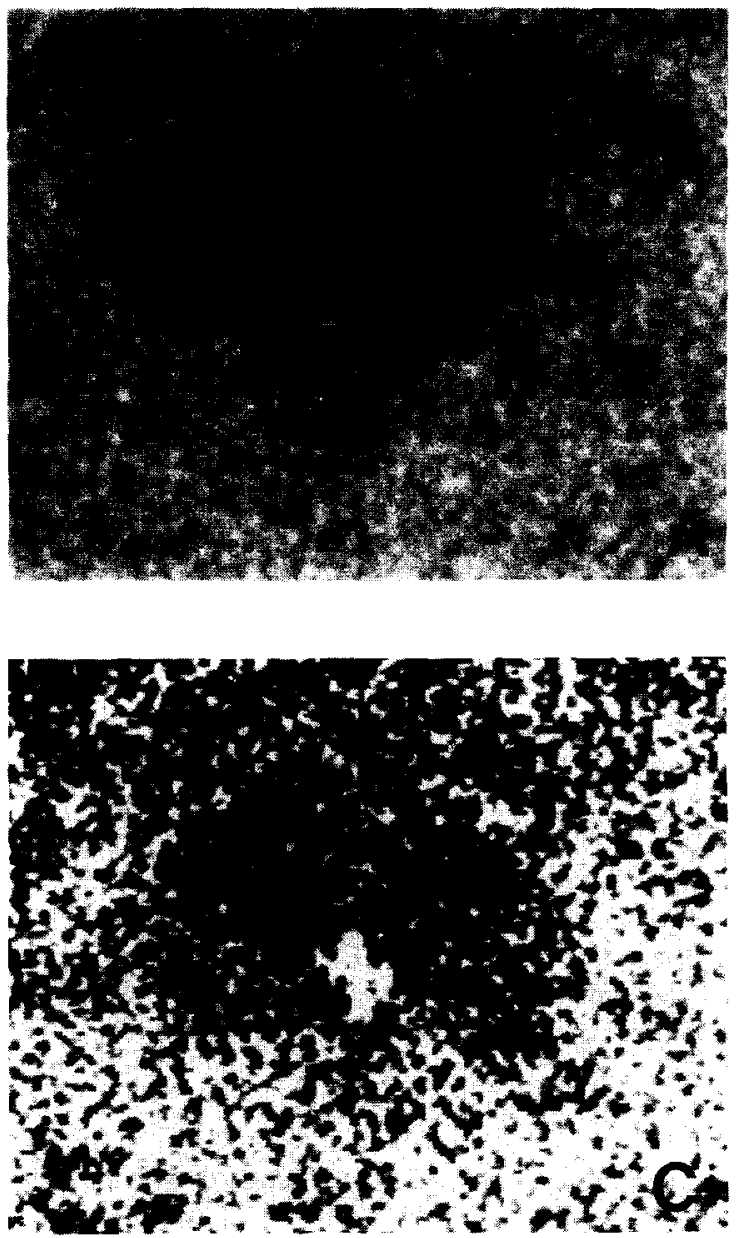

DENSITY OF EAA LIGAND BINDING IN THE SUBDIVISIONS

\begin{tabular}{|c|c|c|c|c|}
\hline PAG subdivision & $\begin{array}{l}\text { NMDA } \\
(n=3)\end{array}$ & $\begin{array}{l}Q A-i \\
(n=4)\end{array}$ & $\begin{array}{l}\mathrm{KA} \\
(n=3)\end{array}$ & $\begin{array}{l}\text { QA-m } \\
(n=4)\end{array}$ \\
\hline Dorsal & $200(20)$ & $779(25)$ & $432(47)$ & $265(27)$ \\
\hline Medial & $247(24)$ & $803(27)$ & $525(51)$ & $303(28)$ \\
\hline Dorsolateral & $280(42)$ & $975(51)$ & $526(53)$ & $387(46)$ \\
\hline Ventrolateral & $181(21)$ & $67 !(21)$ & $405(75)$ & $235(38)$ \\
\hline$\%$ Reference area & $15 \%$ & $31 \%$ & $40 \%$ & $70 \%$ \\
\hline
\end{tabular}

QA and was approximately $50 \%$ of total binding. KA binding sites were measured with $60 \mathrm{nM}\left[{ }^{3} \mathrm{H}\right] \mathrm{KA}$ (spec. act. $=4.4 \mathrm{Ci} / \mathrm{mmol})$ in $50 \mathrm{mM}$ Tris-acetate buffer $(\mathrm{pH}$ 7.2). Non-specific binding was assessed with $100 \mu \mathrm{M} \mathrm{KA}$ and was less than $10 \%$ of total binding. At the end of incubation, all slides received four rapid squirts with $4^{\circ} \mathrm{C}$ buffer and two squirts of $2.5 \%$ glutaraldehyde in acetone. Slides were dried under a hot stream of air, apposed to tritium sensitive film (Hyperfilm, Amersham) and exposed for 2-6 weeks with known radioactive standards. Films were analyzed with computer assisted densitometry (MCID system, Imaging Research, St. Catherines, Ont.). Subdivisions of the PAG as defined by Beitz [3] were used to read films. On all films a reference region of known high binding was read to determine the level of PAG ligand binding relative to maximal levels in brain. For NMDA and QA-i binding sites the reference region was the dentate gyrus of the hippocampus, for
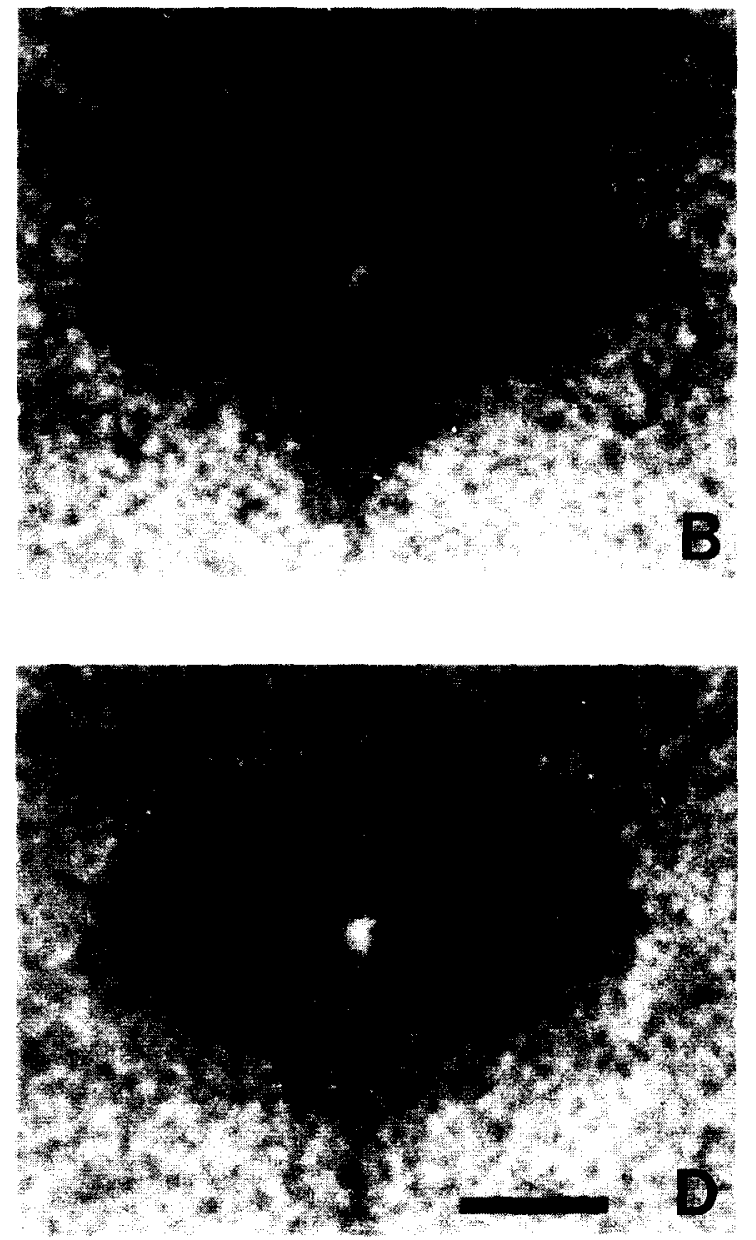

Fig. 1. Autoradiographs of rat periaqueductal gray excitatory amino acid binding sites. All images show total binding without non-specific binding subtraction. A: $N$-methyl-D-aspartate binding sites. B: quisqualate-ionotropic binding sites. C: kainate binding sites. D: quisqualate-metabotropic binding sites. Highest density of binding is seen in the dorsolateral (dl) subdivision and lowest in the ventrolateral (vl) subdivision. (d) is the dorsal subdivision, the medial subdivision surrounds the aqueduct. Bar $=500 \mu \mathrm{m}$. 
KA binding sites the CA3 subfield of the hippocampus, and for QA-m binding sites the superficial layers of the superior colliculus.

All subtypes of EAA binding site were found within the PAG (Table I 1, Fig. 1). The relative density of each binding site subtype as compared with known high density regions varied considerably. NMDA binding sites had the lowest relative density while QA-m had the highest relative density. This single point study does not permit true comparison of the total density of binding site subtypes. QA-i and NMDA binding sites were assayed at ligand concentrations that probably identify only a fraction of total binding sites. The absolute density of NMDA and QA-i binding sites in forebrain is higher than that of KA and QA-m binding sites and while the relative density of KA and QA-m binding sites is high in the PAG, the absolute density of PAG NMDA and QA-i binding sites may be significantly higher than the absolute density of KA and QA-m binding sites. Within the PAG, the distribution of EAA binding site subtypes was inhomogeneous. All EAA binding site subtypes had highest levels of ligand binding in the dorsolateral and medial subdivisions (Table I, Fig. 1) with least binding in the ventrolateral subdivision.

Our results are in general agreement with previous autoradiographic studies of EAA binding sites in the PAG. Prior studies of $\left[{ }^{3} \mathrm{H}\right]$ glutamate binding did not discriminate binding site subtypes but did reveal a moderate density of EAA binding sites in the PAG with the highest density of ligand binding in the dorsolateral subdivision $[10,11]$. Qualitative studies of $\left[{ }^{3} \mathrm{H}\right] \mathrm{KA}$ binding revealed moderate density of KA binding sites in the PAG [17, 22], results consistent with the data we obtained. A previous study of $\left[{ }^{3} \mathrm{H}\right]$ AMPA binding gave significantly lower relative density of QA-i binding sites in the PAG [20] but the incubation solution did not contain KSCN, which significantly enhances AMPA binding [19].

Biochemical, immunocytochemical, and $\left[{ }^{3} \mathrm{H}\right]$ aspartate transport techniques suggest that both $P A G$ afferents and efferents use EAA neurotransmitter(s) $[1,4,7,23]$. We found all subtypes of EAA binding sites within all subdivisions of the PAG. The inhomogeneous distribution of EAA binding sites within the PAG reinforces the concept, previously established by morphometric and functional studies $[3,5,8,9]$ (see Beitz and Shephard [5] for review), that the PAG has distinct subdivisions, though functional studies and anatomic studies do not indicate identical boundaries of subdivisions.

The different EAA receptors have different physiological properties. While KA and QA-i receptors are felt to mediate conventional fast synaptic excitation, NMDA receptors produce an unusual voltage dependent $\mathrm{Ca}^{2+}$ current implicated in persistent synaptic plasticity [18]. Similarly, the nature of the QA-m receptor suggests a role in neuromodulation rather than conventional neurotransmission [21]. With two exceptions, physiological studies of EAA effects within the PAG have used the non-specific agonists glutamate, aspartate, or homocysteate. The presence, however, of all EAA binding site subtypes within the PAG suggests that the role(s) of EAAs in PAG function is(are) likely to be complex. Using NMDA as an agonist and the specific NMDA antagonist AP7, Jaquet specifically implicated NMDA receptors in the antinociceptive effects of EAAs within the PAG [13]. Depaulis et al. have implicated KA receptors in the genesis of intraspecific defensive behaviors [8]. The development of relatively specific antagonists for non-NMDA receptors [12] permits systematic physiological dissection of the function of EAAs within the PAG.

This work was supported by NIH Grants NS 01300 , NS 19613, NS 15655, and the Huntington's Disease Society of America.

1 Beart, P.M., Summers, R.J., Stephenson, J.A., Cook, C.J. and Christie, M.J., Excitatory amino acid projections to the periaqueductal gray in the rat: a retrograde transport study utilizing $D\left[{ }^{3} \mathrm{H}\right]$ aspartate and [ $\left.{ }^{3} \mathrm{H}\right] \mathrm{gaba}$, Neuroscience, 34 (1990) 163-176.

2 Behbehani, M.M. and Fields, H.L., Evidence that an excitatory connection between the periaqueductal gray and nucleus raphe magnus mediates stimulation produced analgesia, Brain Res., 170 (1979) 85-93.

3 Beitz, A.J., The midbrain periaqueductal gray in the rat. I. Nuclear volume, cell number, density, orientation, and regional subdivisions, J. Comp. Neurol., 237 (1985) 445-459.

4 Beitz, A.J., Possible origin of glutamatergic projections to the midbrain periaqueductal gray and deep layer of the superior colliculus of the rat, Brain Res. Bull., 23 (1989) 25-35.

5 Beitz, A.J. and Shepard, R.D., The midbrain periaqueductal grey in the rat. II. A Golgi analysis, J. Comp. Neurol., 237 (1985) 460 475.

6 Cha, J.J., Makowiec, R.L., Penney, J.B. and Young, A.B., L[3H]Glutamate labels the metabotropic excitatory amino acid receptor in rodent brain, Neurosci. Lett., 113 (1990) 78-83.

7 Clements, J.R., Madl, J.E., Johnson, R.L., Larson, A.A. and Beitz, A.J., Localization of glutamate, glutaminase, aspartate, and aspartate aminotransferase in the rat mdibrain periaqueductal gray, Exp. Brain Res., 67 (1987) 594-602.

8 Depaulis, A., Bandler, R. and Vergnes, M., Characterization of pretentorial periaqueductal matter neurons mediating intraspecific defensive behaviors in the rat by microinjections of kainic acid, Brain Res., 486 (1989) 121-132.

9 Fardin, V., Oliveras, J.-L. and Besson, J.-M., A reinvestigation of the analgesic effects induced by stimulation of the periaqueductal gray matter in the rat. II. Differential characteristics of the analgesia induced by ventral and dorsal PAG stimulation, Brain Res., 306 (1984) 125-139.

10 Greenamyre, J.T., Young, A.B. and Penney, J.B., Quantitative autoradiographic distribution of $\mathrm{L}-\left[{ }^{3} \mathrm{H}\right]$ glutamate-binding sites in rat central nervous system, J. Neurosci., 4 (1984) 2133-2144. 
11 Halpain, S., Wieczorek, C.M. and Rainbow, T.C., Localization of L-glutamate receptors in rat brain by quantitative autoradiography, J. Neurosci., 4 (1984) 2247-2258.

12 Honore, T., Davies, S.N., Drejer, J., Fletcher, E.J., Jacobsen, P., Lodge, D. and Nielsen, F.E., Quinoxalinediones: potent competitive non-NMDA glutamate receptor antagonists, Science, 241 (1988) 701-703.

13 Jaquet, Y., The NMDA receptor: central role in pain inhibition in rat periaqueductal gray, Eur. J. Pharmacol., 154 (1988) 271-276.

14 Jensen, T.S. and Yaksh, T.L., Spinal monoamine and opiate systems partly mediate the antinociceptive effects produced by glutamate at brainstem sites, Brain Res., 321 (1984) 287-297.

15 Jensen. T.S. and Yaksh, T.L., Comparison of the antinocicepetive effect of morphine and glutamate at coincidental sites in the periaqueductal gray and medial medulla in rats, Brain Res., 476 (1989) $1-9$.

16 Jurgens, U. and Richter, K., Glutamate-induced vocalization in the squirrel monkey, Brain Res., 373 (1986) 349-358.

17 Monaghan, D.T. and Cotman, C.W., The distribution of [ $\left.{ }^{3} \mathrm{H}\right] \mathrm{kainic}$ acid binding in rat CNS as determined by autoradiography, Brain Res., 252 (1982) 91-100.

18 Monaghan, D.T., Bridges, R.J., and Cotman, C.W., The excitatory amino acid receptors: their classes, pharmacology, and distinct properties in the function of the central nervous system, Annu. Rev. Pharmacol. Toxicol., 29(1989) 365-402.

19 Nielsen, E.O., Cha, J.J., Honore, T., Penney, J.B. and Young. A.B., Thiocyanate stabilizes AMPA binding to the quisqualate receptor, Eur. J. Pharmacol., 157 (1988) 197-203.

20 Rainbow, T.C., Wieczorek, C.M. and Halpain, S., Quantitative autoradiography of binding sites for $\left[{ }^{3} \mathrm{H}\right] \mathrm{AMPA}$, a structural analogue of glutamic acid, Brain Res., 309 (1984) 173-177.

21 Sladeczek, F., Recasens, M. and Bockaert, J., A new mechanism for glutamate receptor action: phosphoinositide hydrolysis, Trends Neurosci., 11 (1988) 545-549.

22 Unnerstall, J.R. and Wamsley, J.K., Autoradiographic localization of high-affinity [ $\left.{ }^{3} \mathrm{H}\right] \mathrm{kainic}$ acid binding sites in the rat forebrain, Eur. J. Pharmacol., 86 (1983) 361-371.

23 Wiklund, L., Behzadi, G., Kalen, P., Headley, P.M., Nicolopoulos, L.S., Parsons, C.G. and West, D.C., Autoradiographic and electrophysiological evidence for excitatory amino acid transmission in the periqueductal gray projection to nucleus raphe magnus in the rat, Neurosci. Lett., 93 (1988) 158-163.

24 Young, A.B. and Fagg, G.E., Excitatory amino acid receptors in the brain: membrane binding and receptor autoradiographic approaches, Trends Physiol. Sci., 11 (1990) 126-133. 